\title{
Tecnofobia - Sobrecarga de Informação
}

\section{Resumo}

Deve-se admitir que há muitos aspectos da era da informação dos anos 90 que continuarão a nos causar ansiedade neste novo século. Sobre alguns destes, temos pouco, ou nenhum controle. Por outro lado, há medidas que podemos tomar para eliminar boa parte, se não toda, essa ansiedade. Portanto, pode-se dizer que sobreviver na era da informação é uma tarefa desafiadora, porém recompensadora.

\begin{abstract}
We should admit that there are so many aspects of the information era referring to the years 90 , that will be continue to cause ourselves anxiety, through the new century. We have about those aspects a few or none control By other side, there are measures we can take on for eliminating in part or for all of that anxiety. Therefore, we can say that surviving in this information era is a challenging task, but rewarding one.
\end{abstract}

\section{Introdução}

Neste século 20, tem havido uma sobrecarga de informação sem precedentes. Seja pela página impressa, rádio, televisão, internet e outros meios, o mundo está saturado de informação. David Shenk escreve em seu livro Data Smog Surviving the Information Glut (Poluição Dados - Como Sobreviver ao Excesso de Informação): "A sobrecarga de informação emergiu como ameaça genuína.... Enfrentamos agora a perspectiva de obesidade de informação".

Veja como simples exemplo um bem-conhecido jornal. Segundo diz, uma edição normal de meio de semana do The New York Times contém mais informação do que o cidadão mediano obteria durante toda a sua vida na Inglaterra do século 17. Mas, além dos diários, revistas e livros de toda sorte e sobre uma profusão de temas, aumenta a avalanche de informações. Novos livros saem às dezenas de milhares por ano. $\mathrm{E}$, com a quantidade de informações científicas dobrando a cada seis anos, não é de espantar que só de revistas técnicas existem mais de 100.000 no mundo. $E$ a Internet coloca um vasto acervo de informações ao alcance de usuários de computador.

E as revistas? Periódicos sobre economia, revistas femininas, revistas para jovens, revistas sobre esportes e lazer - revistas sobre quase todos os temas e interesses humanos — inundam o mundo, todas elas cobrando a nossa atenção. E que dizer do papel do publicitário, "o pregoeiro da nulidade", como muito bem tem sido chamado? Em seu livro Information Anxiety, o autor Richard S. Wurman observa: "As agências de publicidade declararam guerra aos nossos sentidos com uma chuva de anúncios que exigem ser vistos, ouvidos, cheirados e tocados. Elas insistem que você precisa do último produto, do último modelo, para manter-se atualizado".

O psicólogo e pesquisador social australiano Dr. Hugh MacKay disse que "o mundo está sendo inundado por informações, e as pessoas estão sendo induzidas a entrar na via expressa da super-rodovia da informação". O problema, na visão do Dr. MacKay, é que a explosão de notícias e atualidades no rádio e na TV, além da fantástica explosão de redes de informação por computador, resulta num mundo em que muitos assimilam informações da mídia que, realmente muitas vezes, são meras representações parciais dos fatos

*Bacharel em Administração de Empresas pela Faculdade de Administração de Empresas de Santos; Pós-Graduação (Lato-Sensu) em Administração, Informática e Didática do Ensino Superior; Pós-Graduação (Stricto-Sensu) mestrado/doutorado em Administração, Ciência da Computação e Educação (PUC/SP e Mackenzie). Professor das Faculdades Integradas "Campos Salles" 
e dos eventos, não a história inteira.

\section{O que é Informação?}

A palavra básica informare, do latim, tem a idéia de moldar material, como o oleiro faz com o barro. Assim, há definições de "informar" no sentido de "moldar a mente", ou "modelar ou instruir a mente". A maioria dos leitores lembrase muito bem do tempo, não muito remoto, em que "informação" era simplesmente uma lista de fatos ou dados que nos davam detalhes, tais como quem, onde, o que, quando, ou como. Não havia linguagem, ou vocabulário especial para informação. Bastava pedir informações, ou verificá-las pessoalmente.

Mas vieram os anos 90 e o mundo passou a ouvir tantas palavras novas ligadas à informação, que estas, por si só, podem criar confusão. Embora algumas dessas palavras ou expressões sejam relativamente simples e compreensíveis, tais como "infomania", "tecnofilia" e "era da informação”, há outras que podem causar grandes problemas. Hoje, o mundo está sendo invadido pela infomania - a crença de que quem dispõe de mais informações leva vantagem sobre quem tem menos acesso a elas, e que a informação não é mais um meio para um fim, mas um fim em si mesmo.

Essa "mania" é alimentada por uma torrente de sistemas de telecomunicação, como fax, telefone celular e o computador pessoal, tido por alguns como símbolo e mascote da era da informação. É verdade que a conveniência, a velocidade e a capacidade dos computadores têm aberto o acesso a informações como nunca antes tanto que Nicholas Negroponte, do Instituto de Tecnologia de Massachusetts, diz: "Computação não é mais uma questão de computadores. É de rotina de vida". Em resultado, as informações e as tecnologias veiculadoras tornaram-se excessivamente valorizadas, em alguns casos reverenciadas, com enorme séquito de cultuadores em toda a Terra. Programas de notícias e de atualidades na TV gozam de credibilidade quase infalível, ao passo que enxurradas de trivialidades são apresentadas em programas de entrevistas ou semelhantes e engolidas por um público muitas vezes não-crítico e ingênuo.

É devido às mudanças, que a era da informação causou na nossa maneira de viver e de trabalhar, que muitos hoje sofrem de uma ou de outra forma de "ansiedade causada pela informação". Exatamente, que ansiedade é essa? Como saber se ela está nos afetando? Pode-se fazer algo a respeito?

\section{A Informação Causando Ansiedade}

Por que a informação pode causar ansiedade?

"A Informação pode gerar ansiedade devido ao sempre crescente abismo entre o que compreendemos e o que achamos que devíamos compreender. É o buraco negro entre dados e conhecimento, que ocorre quando a informação não nos diz o que queremos, ou precisamos saber". Assim escreveu Richard S. Wurman em seu livro Information Anxiety. "Por muito tempo, as pessoas não se davam conta do quanto não sabiam - não tinham idéia do que não sabiam. Mas, hoje as pessoas sabem o quanto não sabem, e isso as deixa ansiosas". O resultado é que a maioria de nós talvez achemos que devíamos saber mais do que sabemos. Com a torrente de dados que nos chegam, nós captamos unidades de informação. Porém muitas vezes não sabemos bem o que fazer com elas. E talvez achemos que todo mundo sabe e entende muito mais coisas do que nós. É aí que ficamos ansiosos.

David Shenk argumenta que o excesso de informações virou um poluente que produz uma "poluição de dados", e acrescenta: "Essa poluição estorva; elimina momentos de quietude e obstrui a muito necessária contemplação.... Ela nos estressa".

É verdade que o excesso de informações ou uma sobrecarga de matérias pode gerar ansiedade, mas, dá-se o mesmo, caso nos faltem informações ou, pior ainda, se forem incorretas. Ter informações demais é como sentir-se solitário numa sala cheia de gente. Na expressão de John Naisbitt em seu livro Megatrends 
(Megatendências) "estamos atolados em informações, mas esfomeados de conhecimento".

\section{Lixo demais na informação}

"A sociedade, como todos nós sabemos por experiência, está se tornando implacavelmente mais grotesca. Estamos testemunhando o novo reinado do estilo lixo na TV, do ódio no rádio, de radialistas sensacionalistas, da exploração de litígios, dos golpes de publicidade, da retórica excessivamente violenta e sarcástica. Os filmes são cada vez mais sexualmente explícitos e violentos. A publicidade é mais ruidosa, mais invasiva e, não raro, beirando o mau gosto. A profanidade está em alta, a decência em baixa... $\mathrm{O}$ que outros chamam de crise nos valores da família tem mais a ver com a revolução na informação do que com o desrespeito de Hollywood pelo modelo da família tradicional". - Data Smog — Surviving the Information Glut, de David Shenk.

\section{Como os crimes de computador podem afetá-lo}

Outra causa de ansiedade é o surto de crimes de computador. O Dr. Frederick B. Cohen, em seu livro Protection and Security on the Information Superhighway (Proteção e Segurança na SuperRodovia da Informação), expressa sua preocupação: "O FBI [polícia federal americana] estima que todo ano perdem-se US\$ 5 bilhões para os crimes de computador. E, incrivelmente, isso é apenas a ponta do iceberg. Vulnerabilidades nos sistemas de informação também têm sido exploradas para ganhar o controle em negociações, arruinar reputações, ganhar conflitos militares e até cometer assassinatos". Some-se a isso a sempre crescente preocupação com os problemas do acesso de criança à pornografia no computador - sem se mencionar a invasão de privacidade.

Inescrupulosos viciados em computador deliberadamente introduzem "vírus" nos sistemas, causando danos. Criminosos piratas eletrônicos acessam ilegalmente sistemas de computadores e obtêm informações confidenci- ais, às vezes até mesmo furtam dinheiro. Tais atividades podem ter efeitos devastadores sobre milhares de usuários de computadores pessoais. Os crimes de computador são uma ameaça para os negócios e para o governo.

\section{É preciso estar bem-informado}

Naturalmente, todos nós precisamos estar bem-informados, mas dispor de vastas informações não necessariamente nos educa no verdadeiro sentido, pois muito do que se apresenta como informação nada mais é do que meros fatos ou dados aleatórios que nada têm a ver com a nossa experiência. Há até quem sugira que, em vez de "explosão de informação", esse fenômeno devia chamar-se "explosão de dados" ou, mais ironicamente ainda, "explosão da não-informação". É assim que a analista econômica Hazel Henderson vê a questão: "A informação em si não ilumina. Não podemos distinguir com clareza entre má informação, desinformação e propaganda, nesse meio dominado pela mídia. Focalizar na mera informação tem levado à sobrecarga de cada vez menos significativos bilhões de unidades de fragmentados dados aleatórios, em vez de à pesquisa de novos padrões significativos de conhecimento".

Joseph J. Esposito, presidente do Encyclopædia Britannica Publishing Group, avalia com franqueza: "A maior parte das informações da Era da Informação é simplesmente inaproveitada; é apenas barulho. O nome Explosão de Informações cai bem; a explosão obstrui a nossa capacidade de realmente ouvir muita coisa do que quer que seja. Se não se pode ouvir, não se pode conhecer". Orrin E. Klapp avalia: "Suspeito que ninguém saiba o quanto da oferta de comunicações públicas seja pseudo-informação, que aparenta dizer algo, mas, na verdade, nada diz ".

Você sem dúvida se lembra de que boa parte de sua educação escolar centraliza-se em aprender fatos para passar nas provas. Muitas vezes abarrotou seu cérebro de fatos pouco antes da época das provas. Lembra-se de ter decorado uma longa série de datas nas aulas de História? 
Quantos desses eventos e datas se lembra agora? Será que esses fatos o ensinaram a raciocinar e a chegar a conclusões lógicas?

\section{Será que mais é sempre melhor?}

Se não for controlado, o afã por mais informação pode sair muito caro em termos de tempo, sono, saúde e até mesmo dinheiro. Pois, embora mais informação realmente ofereça mais opções, o pesquisador talvez fique ansioso, perguntandose checou ou acessou todas as informações disponíveis. O Dr. Hugh MacKay acautela: "De fato, a informação não é o caminho da iluminação. A informação, em si, não lança luz sobre o sentido da nossa vida. A informação tem pouco a ver com adquirir sabedoria. Realmente, como no caso de outras posses, ela pode servir de obstáculo à sabedoria. É possível saber demais, assim como é possível possuir demais".

Muitas vezes, não é apenas o volume de informações que sobrecarrega as pessoas, mas também a frustração de tentar transformar informações em algo compreensível, significativo e realmente informativo. Tem-se dito que poderíamos ser "como uma pessoa sedenta que fosse obrigada a usar um dedal para beber água de um hidrante de incêndio. $\mathrm{O}$ enorme volume de informações, e o modo como muitas vezes são fornecidas, faz com que boa parte delas nos sejam inúteis". Assim, seja qual for a informação, não deve ser avaliada em termos de volume, mas de qualidade e utilidade para nós pessoalmente.

\section{Que dizer da transferência de dados?}

Outra expressão comum hoje é "transferência de dados". Isso significa transmitir informações eletronicamente. Embora tenha seu valor, não é boa comunicação no sentido mais pleno. Por que não? Porque nós interagimos melhor com pessoas do que com máquinas. Na transferência de dados, não há expressões faciais, contato olho no olho nem linguagem corporal, que tantas vezes moldam a conversação e comunicam senti- mentos. Na conversa face a face, esses fatores enriquecem e muitas vezes elucidam as palavras. Nenhuma dessas ajudas valiosas ao entendimento existem na comunicação eletrônica, nem mesmo no cada vez mais popular telefone celular. Às vezes, nem mesmo a conversa face a face comunica as reais intenções do interlocutor. $\mathrm{O}$ ouvinte talvez ouça e interprete as palavras à sua maneira e lhes dê o sentido errado. Quanto maior é esse perigo, quando não se vê o interlocutor!

É um fato lamentável da vida que o tempo excessivo que alguns passam na frente do computador ou da televisão, às vezes faz dos membros da família estranhos dentro de sua própria casa.

\section{Já ouviu falar de tecnofobia?}

"Tecnofobia" significa simplesmente "medo da tecnologia", que inclui o uso de computadores e de aparelhos eletrônicos similares. Há quem acredite que essa seja uma das ansiedades mais comuns causadas pela era da informação. Um artigo no jornal The Canberra Times, baseado numa notícia da Associated Press, diz: "Executivos japoneses temem os computadores". Foi dito a respeito do diretor executivo de uma grande empresa japonesa: "[Ele] inspira poder e prestígio. Mas, coloque-o na frente de um computador e ele tremerá de nervoso". Uma pesquisa em 880 empresas japonesas revelou que apenas 20\% de seus executivos sabem usar computadores.

A tecnofobia é estimulada por grandes desastres, como o colapso dos telefones na cidade de Nova York em 1991, que paralisou aeroportos locais por várias horas. E que dizer do acidente na Usina Nuclear Three Mile Island, nos Estados Unidos, em 1979? Os operadores da usina levaram várias horas cruciais para decifrar o significado de alarmes controlados por computadores.

Esses são apenas alguns exemplos de como a tecnologia da era da informação afetou dramaticamente a humanidade. Em seu livro, o Dr. 
Frederick B. Cohen faz as seguintes perguntas, que dão o que pensar: "Tem ido ao banco ultimamente? Se os computadores não estivessem funcionando, conseguiria retirar algum dinheiro? E no supermercado? Seriam capazes de relacionar as suas compras e dar o custo total sem os computadores?"

Você, identifique-se com uma ou mais das seguintes situações imaginárias:

- Seu novo videocassete parece ter botões demais, quando você deseja selecionar um programa para gravar. Meio sem jeito, você chama seu sobrinho de nove anos para programar o aparelho ou, então, decide que, afinal, esse programa não é tão interessante assim.

- Você precisa com urgência de dinheiro. Vai de carro até o "caixa automático" mais próximo, mas, de repente, você se lembra de que, na última vez que usou o caixa eletrônico, você se confundiu e apertou os botões errados.

- O telefone do escritório toca. A ligação veio para você por engano. A chamada era para seu chefe, no andar de cima. É muito simples transferir a ligação, mas, inseguro, você prefere que a telefonista o faça.

- O painel de seu carro novo mais parece a cabina de um moderno avião a jato. De repente, acende uma luz vermelha e você fica ansioso sem saber o que ela significa. Daí é preciso consultar um detalhado manual.

Esses são apenas alguns exemplos de tecnofobia. A tecnologia com certeza continuará a desenvolver equipamentos ainda mais sofisticados, que as pessoas de gerações passadas sem dúvida chamariam de "milagrosos". Cada novo produto atualizado que chega ao mercado exige maiores conhecimentos para ser usado eficazmente. Os manuais, escritos por especialistas que usam jargões ${ }^{1}$, tornam-se assustadores em si mesmos, pois se presume que o usuário entende o vocabulário e possui certos conhecimentos e habilidades.

O teórico em informação Paul Kaufman resume assim a situação: "A nossa sociedade tem uma imagem da informação que, embora sedutora, em última análise é contraproducente... Uma das razões é que se deu atenção demais aos componentes materiais dos computadores e pouco demais às pessoas que efetivamente usam as informações para atender o mundo e fazer coisas úteis umas para as outras.... O problema não é que tenhamos os computadores em tão alta estima, mas que viemos a pensar menos nos humanos". Parece mesmo que a preocupação com a glória de produzir uma formidável tecnologia nova deixa muitas pessoas apreensivas com o que vem a seguir. Edward Mendelson diz: "Os visionários da tecnologia jamais sabem distinguir entre o exeqüivel e o desejável. Se for possível fazer uma máquina realizar alguma tarefa estupendamente complexa, o visionário logo supõe que essa tarefa seja meritória".

É esse descaso pelo elemento humano na tecnologia que agrava muito a ansiedade causada pela informação.

\section{A produtividade aumenta mesmo?}

O colunista Paul Attewell, escrevendo em The Australian, comenta a sua pesquisa sobre quanto tempo e dinheiro têm sido poupados pelos computadores nos anos recentes. Eis algumas de suas colocações interessantes: "Apesar de anos de investimentos em sistemas de computação programados para realizar tarefas administrativas e diminuir os custos, muitas universidades e escolas verificam que seus quadros administrativos continuam a aumentar... Por várias décadas, os fabricantes de computadores vêm afirmando que, a tecnologia que vendem aumenta muito a produtividade, permitindo que certo volume de serviços administrativos seja executado por bem menos trabalhadores a um custo bem menor. Em vez disso, como estamos vendo, a tecnologia da informação tem levado a uma deslocação de serviços, ou seja: muitas coisas novas estão sendo feitas por equipes do mesmo tamanho, ou maiores, em vez de o velho serviço ser feito por menos empregados. E, muitas vezes, sem nenhuma

${ }^{1}$ Exemplos de jargões de computador, em inglês; long on, "conectar ao sistema"; boot up, "iniciar ou colocar em movimento"; portrait position, "vertical"; landscape position, "horizontal". 
redução de custos. Um exemplo dessa deslocação é o uso da tecnologia, para melhorar o aspecto da papelada, em vez de simplesmente produzi-la mais depressa".

Parece que a super-rodovia da informação, potencialmente perigosa para todos, veio para ficar. Mas, como podemos evitar a ansiedade mesmo que pequena?

\section{Conclusão}

Ansiedade de informação é o produto de uma era de informação que nos pegou despreparado e ansiosos. Talvez essa ansiedade nos inspire a descobrir novas formas de produzir e compreender informação que reflitam o papel crescente por ela desenpenhado em nossa vida. Talvez nos habituemos a viver em uma sociedade de informação. À medida que a era da informação amadurecer, também nós, como processadores de informação, amadureceremos.

\section{REFERÊNCIAS BIBLIOGRAFICAS}

MARTIN, James - A grande transição. Trad. Priscilla Martins Celeste, São Paulo: Ed. Futura, 1996.

OLIVEIRA, Jayr F. - Uma reflexão do impactos da tecnologia da informação no Brasil: a visão da sociedade, das empresas e dos sindicatos. São Paulo: Érica, 1999.

TENNER, Edward - A vingança da tecnologia. Trad. Ronaldo Sérgio de Biasi. Rio de Janeiro: Campus, 1997.

WURMAN, Richard S. - Ansiedade de informação: como transformar informação em compreensão. Trad. Cultura Editores Associados, São Paulo: Cultura, 1995. 